\title{
Prediction of a new broad-spectrum reactivator capable of reactivating acetylcholinesterase inhibited by nerve agents
}

\author{
Vlastimil Dohnal ${ }^{1}$, Kamil Kuča ${ }^{2}$, Daniel Jun ${ }^{2}$ \\ ${ }^{1}$ Department of Food Technology, Faculty of Agronomy, Mendel University of Agriculture and Forestry, Brno, \\ Czech Republic \\ ${ }^{2}$ Department of Toxicology, Faculty of Military Health Sciences, University of Defence, Hradec Králové, Czech \\ Republic
}

Received $23^{\text {rd }}$ May 2005.

Published online $10^{\text {th }}$ September 2005.

\begin{abstract}
Summary
A methodology combining molecular structure represented by fragments, and artificial neural network $(A N N)$ was applied for the prediction of a new acetylcholinesterase (AChE; EC 3.1.1.7) reactivator. We searched for a new structure of the AChE reactivator with the capability of reactivating AChE inhibited by almost all actual nerve agents. For this purpose, we have tested in vitro seventeen potential AChE reactivators for reactivation of $\mathrm{AChE}$ inhibited by sarin, cyclosarin, agent VX and tabun. The results obtained were used as input data for prediction by ANN. Using ANN we have predicted new AChE reactivators.
\end{abstract}

Key words: oxime - acetylcholinesterase - reactivation - artificial neural networks - organophosphates - QSAR

\section{INTRODUCTION}

Nerve agents such as sarin, tabun, cyclosarin or agent VX are in some countries included as warfare chemical compounds (Bajgar 2004). They are powerful inhibitors of cholinesterases, especially acetylcholinesterase (AchE; EC 3.1.1.7), the enzyme splitting acetylcholine at cholinergic synapses. In the case of the AChE inhibition, ace-

$\triangle \quad$ Kamil Kuča, Department of Toxicology, School of Military Health Sciences, Třebešská 1575, University of Defence, 50001 Hradec Králové, Czech Republic

맸 kucakam@pmfhk.cz tylcholine accumulates itself at nerve synapses and hyperstimulates post-synaptic cholinergic receptors. Afterwards, a cholinergic crisis occurs (Patočka et al. 2004).

These compounds pose an increasing threat in the world due to their possible use in war conflicts ("Gulf war"; Iraq 1990-1991) or in terrorist acts (The sect Aum Shinri Kyo, Japan, 1994, 1995).

From the chemical point of view, these substances are alkylphosphates, alkylphosphonates or their thioanalogues. Their inhibition effect is caused by phosphorylation, respective phosphonylation of serine hydroxy group in the active enzyme site (Fig.1) (Kuča et al. 2003).

The standard treatment for nerve agent intoxications involves the administration of atropine and AChE reactivators (Marrs 1993). 
Pralidoxime

[2-hydroxyiminomethyl-1methylpyridinium chloride], obidoxime [1,3-bis(4hydroxyiminomethylpyridinium)-2-oxapropane

dichloride] and oxime HI-6 [1-(2hydroxyiminomethylpyridinium)-3-(4-

carbamoylpyridinium)-2-oxapropane dichloride]

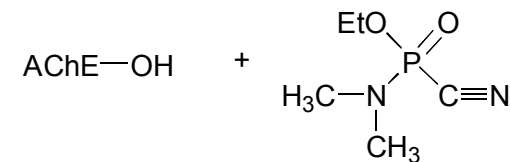

Intact enzyme

Tabun
Fig. 1. Inhibition of acetylcholinesterase by tabun
Scientists have attempted for centuries to develop drugs with targeted effects. Today, with data stored in knowledge bases and with the high computing power of common computers, is easier to reach this aim. Mathematical tools are involved in the search for (quantitative) structure-activity relationships to build (Q)SAR models. Different are the most well known representatives of $\mathrm{AChE}$ reactivators (Kassa 2002). Unfortunately, none of the currently used AChE reactivators is able to reactivate $\mathrm{AChE}$ in all nerve agents used (Kuča et al. 2005).

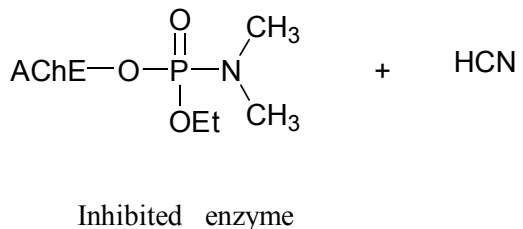

methods are applied to realize these models, starting with simple linear or multilinear methods (Hemmateenejad et al. 2002), through partial least squares methods (Wold et al. 2001) and finishing with artificial intelligence methods (Hemmateenejad 2005).

Table 1. Reactivation potency of tested $\mathrm{AChE}$ reactivators

\begin{tabular}{llllll}
\hline & Oxime & Sarin & Cyclosarin & VX & Tabun \\
\hline $\mathbf{1}$ & BI-6 & 32 & 57 & 46 & 3 \\
$\mathbf{2}$ & TO092 & 44 & 0 & 77 & 8 \\
$\mathbf{3}$ & TO029 & 44 & 0 & 70 & 0 \\
$\mathbf{4}$ & TO063 & 16 & 0 & 26 & 2 \\
$\mathbf{5}$ & TO058 & 25 & 0 & 46 & 9 \\
$\mathbf{6}$ & Obidoxime & 41 & 0 & 79 & 0 \\
$\mathbf{7}$ & TO046 & 54 & 0 & 72 & 46 \\
$\mathbf{8}$ & Pralidoxime & 36 & 3 & 44 & 1 \\
$\mathbf{9}$ & Methoxime & 21 & 32 & 45 & 0 \\
$\mathbf{1 0}$ & TO047 & 34 & 0 & 41 & 8 \\
$\mathbf{1 1}$ & TO052 & 44 & 3 & 71 & 8 \\
$\mathbf{1 2}$ & Trimedoxime & 76 & 0 & 85 & 41 \\
$\mathbf{1 3}$ & TO057 & 30 & 8 & 26 & 8 \\
$\mathbf{1 4}$ & HI-6 & 40 & 58 & 59 & 2 \\
$\mathbf{1 5}$ & TO020 & 4 & 0 & 6 & 6 \\
$\mathbf{1 6}$ & 4-PAM & 16 & 3 & 35 & 6 \\
$\mathbf{1 7}$ & TO033 & 22 & 0 & 20 & 2 \\
\hline
\end{tabular}

Artificial neural networks (ANN) are a group forming one of these artificial intelligence methods. They were introduced in the 40 's of the past century (McCulloch and Pitt 1943) and during the last thirty years a number of different kinds of ANN were developed, which are applicable in many areas of science. They are used very often for the modeling of very complex problems, in areas such as ecology (Lek and Guégan 1999), weather forecasting (Ramírez et al. 2005), prediction of volcanic activity (Luongo et al. 2004), pharmacology (Turner et al. 2004), toxicology (Hemmateenejad 2005) and chemistry (Dohnal et al. 2003, BrodnjakVončina et al. 1999). They are applied especially in 
Monoquaternary AChE reactivators

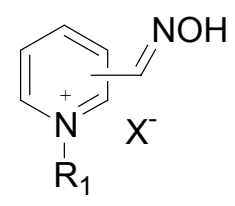

\begin{tabular}{|c|c|c|}
\hline Oxime & $\begin{array}{c}\text { Position of } \\
\text { the oxime group }\end{array}$ & $\begin{array}{c}\text { Substituent located on nitrogen } \\
\text { of the pyridinium ring (R) }\end{array}$ \\
\hline Pralidoxime & 2 & $-\mathrm{CH}_{3}$ \\
\hline TO 020 & 2 & $-\mathrm{CH}_{2}-\mathrm{Ph}$ \\
\hline 4-PAM & 4 & $-\mathrm{CH}_{3}$ \\
\hline TO 063 & 4 & $-\left(\mathrm{CH}_{2}\right)_{5}-\mathrm{CH}_{3}$ \\
\hline
\end{tabular}

Bisquaternary AChE reactivators

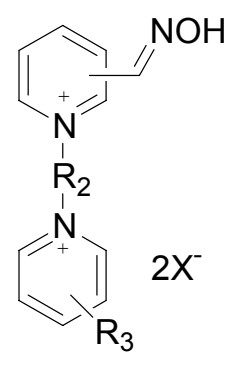

\begin{tabular}{|c|c|c|c|}
\hline Oxime & $\begin{array}{c}\text { Position } \\
\text { of the oxime } \\
\text { group }\end{array}$ & $\begin{array}{l}\text { Substituent located on the second } \\
\text { pyridinium ring }\left(\mathrm{R}_{3}\right)\end{array}$ & $\begin{array}{l}\text { Chemical structure of the bridge } \\
\qquad\left(\mathrm{R}_{2}\right)\end{array}$ \\
\hline TO 033 & 4 & $4-\mathrm{CH}=\mathrm{NOH}$ & $-\left(\mathrm{CH}_{2}\right)_{6^{-}}$ \\
\hline TO 047 & 4 & $4-\mathrm{CH}=\mathrm{NOH}$ & $-\left(\mathrm{CH}_{2}\right)_{5^{-}}$ \\
\hline TO 046 & 4 & $4-\mathrm{CH}=\mathrm{NOH}$ & $-\left(\mathrm{CH}_{2}\right)_{4-}^{-}$ \\
\hline Trimedoxime & 4 & $4-\mathrm{CH}=\mathrm{NOH}$ & $-\left(\mathrm{CH}_{2}\right)_{3-}$ \\
\hline TO 029 & 4 & $4-\mathrm{CH}=\mathrm{NOH}$ & $-\left(\mathrm{CH}_{2}\right)_{2-}^{-}$ \\
\hline Methoxime & 4 & $4-\mathrm{CH}=\mathrm{NOH}$ & $-\left(\mathrm{CH}_{2}\right)_{1-}^{-}$ \\
\hline TO 057 & 4 & $4-\mathrm{CH}=\mathrm{NOH}$ & $-\mathrm{CH}_{2}-\mathrm{CH}_{2}-\mathrm{SO}_{2}-\mathrm{CH}_{2}-\mathrm{CH}_{2}-$ \\
\hline TO 058 & 4 & $4-\mathrm{CH}=\mathrm{NOH}$ & $-\mathrm{CH}_{2}-\mathrm{CH}_{2}-\mathrm{S}^{+}\left(\mathrm{CH}_{3}\right)-\mathrm{CH}_{2}-\mathrm{CH}_{2}-$ \\
\hline Obidoxime & 4 & $4-\mathrm{CH}=\mathrm{NOH}$ & $-\mathrm{CH}_{2}-\mathrm{O}-\mathrm{CH}_{2-}$ \\
\hline TO 052 & 4 & $4-\mathrm{CH}=\mathrm{NOH}$ & $-\mathrm{CH}_{2}-\mathrm{CO}-\mathrm{CH}_{2-}$ \\
\hline BI-6 & 2 & $4-\mathrm{CONH}_{2}$ & $-\mathrm{CH}_{2}-\mathrm{CH}=\mathrm{CH}-\mathrm{CH}_{2-}$ \\
\hline HI-6 & 2 & $4-\mathrm{CONH}_{2}$ & $-\mathrm{CH}_{2}-\mathrm{O}-\mathrm{CH}_{2}-$ \\
\hline TO 092 & 4 & $-\mathrm{H}$ & $-\left(\mathrm{CH}_{2}\right)_{3-}$ \\
\hline
\end{tabular}

Fig. 2. Structures of tested AChE reactivators

chemistry in the optimization of chemical processes (Farková et al. 1999), analytical method development (Hameda et al. 2005) or for QSAR modeling (Hemmateenejad 2005).

In this work, we were interested in the rational prediction of new $\mathrm{AChE}$ reactivators able to reactivate broader spectra of nerve agent inhibitions (sarin, cyclosarin, VX and tabun). For the rational prediction we have used ANN. Results from the in vitro experiments were used as the input data for the ANN.

\begin{abstract}
ANN THEORY
The principles of ANN have been reviewed elsewhere (Basheer and Hajmeer 2000). Some brief information about the ways in which ANN is used will be given below. The kind of ANN called backpropagation multilayer perceptrons (BP-MLP) (McClelland and Rumelhart 1988) was selected as appropriate for the QSAR modeling. The ANN consists of elementary computing units called
\end{abstract}




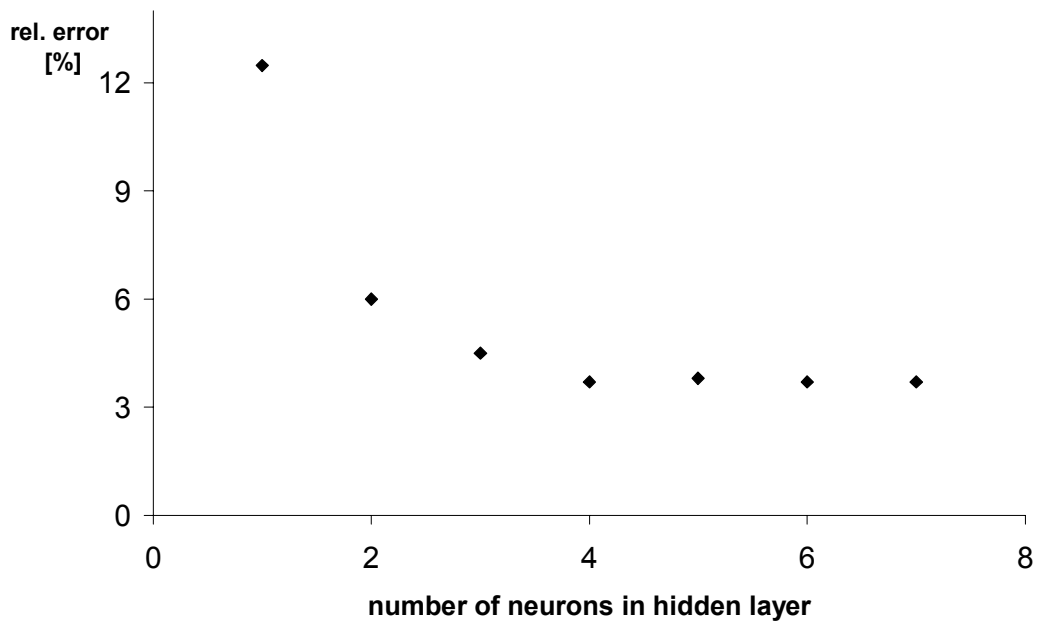

Fig. 3. Plot of the dependence of the error of training and verification data set on the number of ANs in the hidden layer

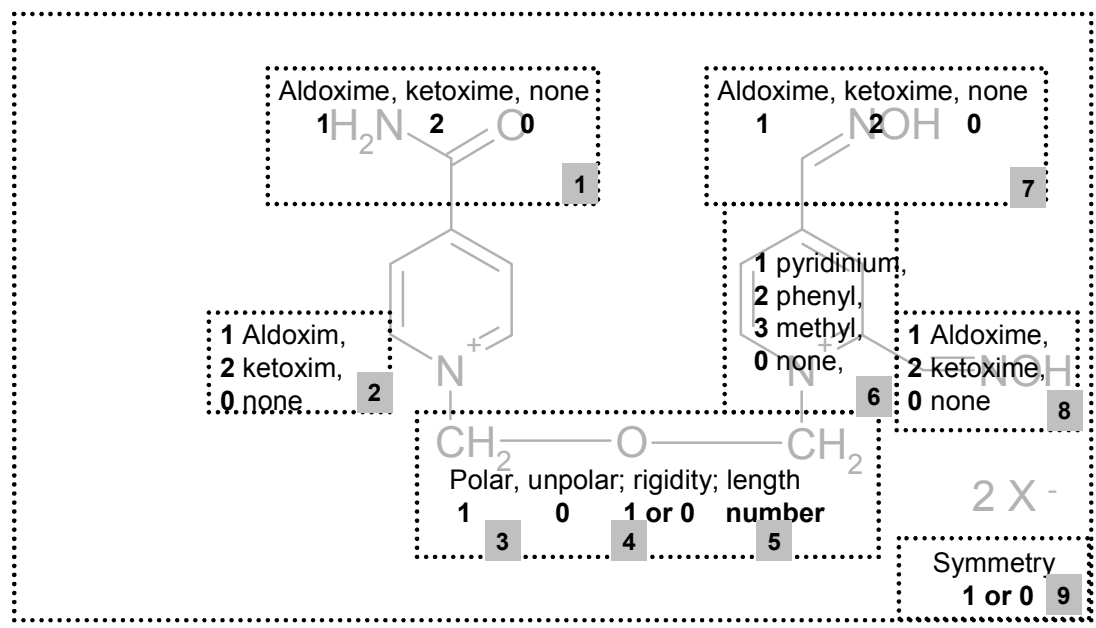

\begin{tabular}{ll} 
& Number of descriptor in vector \\
1 & Code \\
\hdashline$\ldots .$. & Fragment
\end{tabular}

Fig. 4. The fragment-based molecular structure encoding algorithm

artificial neurons (AN). The connections between neurons are weighted by weight coefficients, which determine their importance. In the ANs, the sum of weighted outputs of ANs from previous layers is calculated and when it it is higher than a certain value, bias, it is transformed by the "transfer" function and distributed to the ANs in the next layer. The ANs are sorted into three fully interconnected layers. The first one serves for the input of data, the second one, a hidden layer, is used for the calculations and the third one, output layer, provides the output of calculated results.

For the weights and biases adjustment the back propagation adaptation algorithm was applied. It is the most common algorithm, which is based on the gradient methods. Briefly, the outputs of ANN are calculated, then compared with the targeted outputs and based on the sum of squares of differences for all of the outputs, the weight coefficients and biases are adjusted in the direction from the output layer toward $\mathrm{AN}$ in input layer. That is the reason for the name back propagation.

The work with ANN has two stages adaptation and prediction. During the adaptation phase, the best ANN architecture is searched for, while in the prediction phase only the calculation with the adapted ANN is performed. Mathematically, the sum of squares of differences 

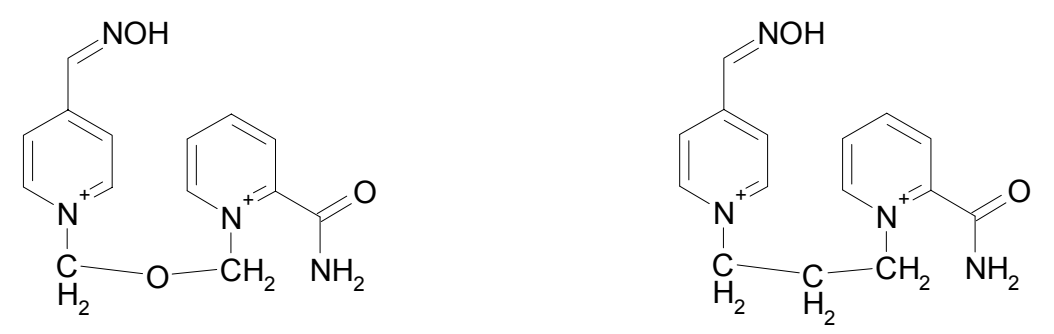

Fig. 5. Predicted new efficient $\mathrm{AChE}$ reactivators against multiple warfare agents

between the targeted and calculated outputs is minimized. The ANN with the lowest and acceptable error rate for all the patterns is considered as successfully adapted. The problem of "overtraining" can occur, when the ANN shows low errors for all patterns, but is missing the property of generalization. It simply reproduces the data used in adaptation. The division of data set to two or more data subsets can avoid this to reach an unwanted result. The first data subset is called the training set. It is used only for calculation for adjustment of weight coefficients and biases. The second part of the data set, the verification set, is used for the verification of adaptation process, to monitor the generalization ability of ANN during the adaptation. The minimum errors for both data subsets assure the correctness of adaptation. In addition, in some work one more data subset is used, - the test set, similar to the verification set for the monitoring of the adaptation process.

\section{SOFTWARE}

The program package PDP++ (http://www.cnbc.cmu.edu/Resources/PDP++//PDP ++ .html), a new generation of the original software package of McClelland and Rumelhart (McClelland et al. 1987), was used for the simulation of ANN. The package contains nine modules, including the bp++ module, which simulates BP-MLP.

\section{THE EXPERIMENT}

In vitro experiment

Seventeen potential AChE reactivators were synthesized in our laboratory. Their chemical structures are shown in Fig. 2. All of them are mono or bisquaternary pyridinium aldoximes with nucleophilic oxime group. The reactivation efficacy was measured using the standard in vitro method (Kuča and Kassa 2003).
The nerve agents used (sarin, cyclosarin, VX and tabun) were of $89-95 \%$ purity. They were obtained from the Military Technical Institute (Zemianské Kostolany, Slovak Republic). All other chemicals of a reagent grade were obtained from commercial sources.

The general conditions of the in vitro method were taken as follows. Rat brain homogenate diluted in distilled water $(10 \%, w / v)$ was used as a source of AChE. Measurement was taken at $25{ }^{\circ} \mathrm{C}$, $\mathrm{pH} 8$, and the concentration of the AChE reactivators was $10^{-3} \mathrm{M}$. Rat brain homogenate was inhibited for $30 \mathrm{~min}$ with the appropriate nerve agent. The AChE reactivator was then added. After $10 \mathrm{~min}$ of incubation, the activity of AChE was determined by $\mathrm{pH}$ static titration of acetic acid released from acetylcholine iodide using the autotitrator (Copenhagen, Danmark).

The percentages of reactivation obtained for all tested AChE reactivators are shown in tab. 1.

\section{ANN DESCRIPTION}

The chemical structures of all compounds exhibit similar fragments. The molecular fragment coding method was used for the transformation of molecular structures. Each molecule was then represented as the vector of 9 descriptors. The assignment of descriptors for the molecular fragments is depicted in detail on Fig. 4. Before the ANN application, the data were scaled to be in the range from 0 to 1 . The data set, containing in total 17 compounds, was divided into 2 subsets, the training with 13 and the verification with 4 patterns.

The optimal ANN consisted of 9 ANs in the input layer (9 molecular descriptors), 4 ANs in the hidden layer and $4 \mathrm{ANs}$ in the output layer. The chart showing the dependence of the error of training and verification data set as the function of number of ANs in the hidden layer of BP-MLP is presented in Fig. 3. The adapted ANN showed a sufficient error for both of the training and 
verification data sets lower than $7 \%$. More ANNs were found with the same architectures, which produced similar results.

Five of them were used for the prediction. The data set for the prediction contained all possible combinations of fragments and the structures with the highest predicted reactivation efficacies for all of the nerve agents were selected (Fig. 5).

\section{CONCLUSION}

The ANNs were used for the prediction of new efficient reactivators for the acetylcholinesterase inhibited by four different nerve agents. The molecular fragment-coding algorithm was used for the structure representation. The ANN was successfully adapted using a very low number of data. New potential efficient $\mathrm{AChE}$ reactivators were predicted using adapted ANN. In future, these predicted compounds will be synthetized and tested.

\section{ACKNOWLEDGEMENT}

The authors express their appreciation to Mrs. M. Hrabinová for her excellent technical assistance during biological testing. The study was supported by grants of Ministry of Defense No. ONVLAJEP 20031 and No.OBVLAJEP 20032.

\section{REFERENCES}

Bajgar J.: Organophosphates/nerve agent poisoning: mechanism of action, diagnosis, prophylaxis, and treatment. Adv. Clin. Chem. 38:151-216, 2004.

Basheer I.A., Hajmeer M.: Artificial neural networks: fundamentals, computing, design, and application. J. Microbiol. Methods 43:3$31,2000$.

Brodnjak-Vončina D., Dobčnik D., Novič M., Zupan J.: Determination of concentrations at hydrolytic potentiometric titrations with models made by artificial neural networks. Chemom. Intell. Lab. Syst. 47:79-88, 1999.

Dohnal V., Zhang F., Li H., Havel J.: Quantitative chiral analysis in capillary electrophoresis from unresolved peaks using derivative electropherograms, experimental design, and artificial neural networks. Electrophoresis 24:2462-2468, 2003.
Farková M., Peña E.M., Havel J.: Use of artificial neural networks in capillary zone electrophoresis. J. Chromatogr. A 848: 365374, 1999.

Hameda A.B., Elosta S., Havel J.: Optimization of the capillary zone electrophoresis method for Huperzine A determination using experimental design and artificial neural networks. J. Chromatogr. A - in press.

Hemmateenejad B.: Correlation ranking procedure for factor selection in PC-ANN modeling and application to ADMETox evaluation. Chemom. Intell. Lab. Syst. 75:231-245, 2005.

Hemmateenejad B., Miri R., Akhond M., Shamsipur M.: QSAR study of the calcium channel antagonist activity of some recently synthesized dihydropyridine derivatives. An application of genetic algorithm for variable selection in MLR and PLS methods. Chemom. Intell. Lab. Syst. 64:91-99, 2002.

Kassa J.: Review of oximes in the antidotal treatment of poisoning by organophosphorus nerve agents. J. Toxicol. Clin. Toxicol. 40:803-816, 2002.

Kuča K., Kassa J.: A comparison of the ability of a new bispyridinium oxime-1-(4hydroxyiminomethylpyridinium)-4-(4-

carbamoylpyridinium) butane dibromide and currently used oximes to reactivate nerve agent-inhibited rat brain acetylcholinesterase by in vitro methods. J. Enz. Inh. Med. Chem. 18:529-535, 2003.

Kuča K., Bielavský J., Cabal J., Kassa J.: Synthesis of a new reactivator of tabun inhibited acetylcholinesterase. Bioorg. Med. Chem. Lett. 13:3545-3547, 2003.

Kuča K., Cabal J., Bajgar J., Jun D.: In vitro searching for a new potent reactivator of acetylcholinesterase inhibited by nerve agent VX. Lett. Drug Design Discovery. 2:23-25, 2005.

Lek S., Guégan J.F.: Artificial neural networks as a tool in ecological modelling, an introduction. Ecol. Modell. 120:65-73, 1999.

Luongo G., Marandola C., Mazzarella A.: Neural forecasting of seismicity and ground displacements in different volcanic areas. J. Volcan. Geotherm. Res. 130:133-146, 2004.

Marrs T.C.: Organophosphate poisoning. Pharmacol. Ther.. 58:51-66, 1993.

McClelland J.L., Rumelhart D.E.: Explorations in Parallel Distributed Processing., MIT Press, Cambridge, 1988.

McCulloch W., Pitts W.: A logical calculus of the ideas immanent in nervous activity. Bull. Math. Biophys. 5:115-133, 1943. 
Patočka J., Kuča K., Jun D.: Acetylcholinesterase: crucial enzyme of human body. Acta Medica (Hradec Králové) 47:215-230, 2004.

Ramírez M.C.V., Velho H.F.C., Ferreira N.J.: Artificial neural network technique for rainfall forecasting applied to the São Paulo region. J. Hydrology 301:146-162, 2005.
Turner J.V., Maddalena D.J., Cutler D.J.: Pharmacokinetic parameter prediction from drug structure using artificial neural networks. Int. J. Pharm., 270:209-219, 2004.

Wold S., Sjöström M., Eriksson L. PLS-regression: a basic tool of chemometrics. Chemom. Intell. Lab. Syst. 58:109-130, 2001. 